Supporting information

\title{
Halogens in protein-ligand binding mechanism: a structural perspective
}

\author{
Nicolas K. Shinada ${ }^{\dagger, \neq, \uparrow, \S}$, Alexandre G. de Brevern ${ }^{*, \neq, \uparrow, \S}$, and Peter Schmidtke ${ }^{*,+}$
}

†Discngine SAS, 79 Avenue Ledru Rollin, 75012 Paris, France

‡Biologie Intégrée du Globule Rouge UMR S1134, Inserm, Univ. Paris Diderot, Sorbonne Paris Cité,

Univ. de la Réunion, Univ. des Antilles, 75739 Paris, France

Il Laboratoire d'Excellence GR-Ex, 75739 Paris, France

§Institut National de la Transfusion Sanguine (INTS), 75739 Paris, France

To whom correspondence should be addressed: nicolas.shinada@inserm.fr

\section{$\underline{\text { Table of contents }}$}

Figure S1. Electrostatic Surface Potential of $\mathrm{F}_{2} \mathrm{CO}$ and 1,4-DITFB

Figure S2. 3D representation of Dasatinib and Indomethacin ligands interacting through their halogen atom

Figure S3. Schematic representation of recurrent molecular fragments containing halogen atoms 3

Figure S4. Quantitative distribution of protein atoms detected in the vicinity of each halogen using a distance-based detection method

Figure S5. 3D representation of fluorine interacting with multiple positive dipole moments of amide carbon in peptide

Figure S6. 3D Illustration of hydrophobic-rich environment surrounding halogen atoms

Figure S7. Distribution of geometric descriptors of polar contact surrounding neutral surface of heavy halogens

Figure S8. Evolution of halogen atom prevalence in RCSB PDB ligand entries per year and per element

Figure S9. Superposed binding modes of dimethylisoxazol on bromodomain-containing protein 2 highlighting the variable spatial position of its chlorine atom

Figure S10. 2D representation of isosceles rule used to define halogen surface accessibility

Figure S11. Representation of generated vectors to assess angles between two interacting atoms 11

Table S1. Occurrences of highly recurrent protein observed in our dataset complexed with halogenated ligand and their corresponding medical application

Table S2. Number of observations per protein and halogen where halogen bonds were detected in our dataset

Table S3. Comparison of halogen - aromatic contacts detected with different detection methods 

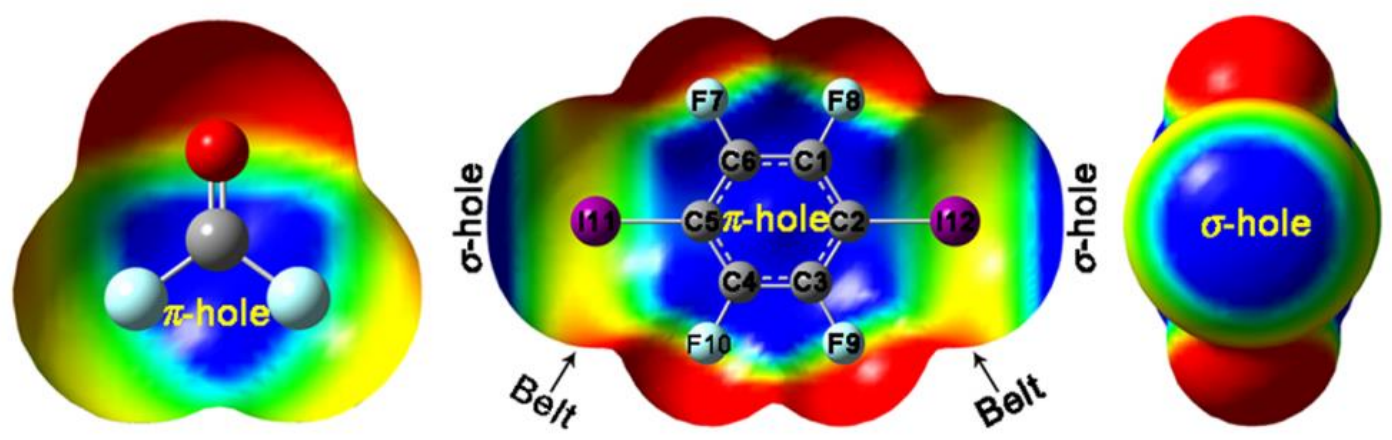

Figure S1. Electrostatic Surface Potential (ESP) of $\mathrm{F}_{2} \mathrm{CO}$ and 1,4-DITFB calculated by Wang group ${ }^{44}$ : positive regions are displayed in blue while electron-rich region are highlighted in red. Computed magnitudes of surface potential for $\mathrm{F}_{2} \mathrm{CO} \pi$-hole Is $185.3 \mathrm{~kJ} / \mathrm{mol}$ and $54.4 \mathrm{~kJ} / \mathrm{mol}$ for 1,4-DITFB $\pi$ hole region. 

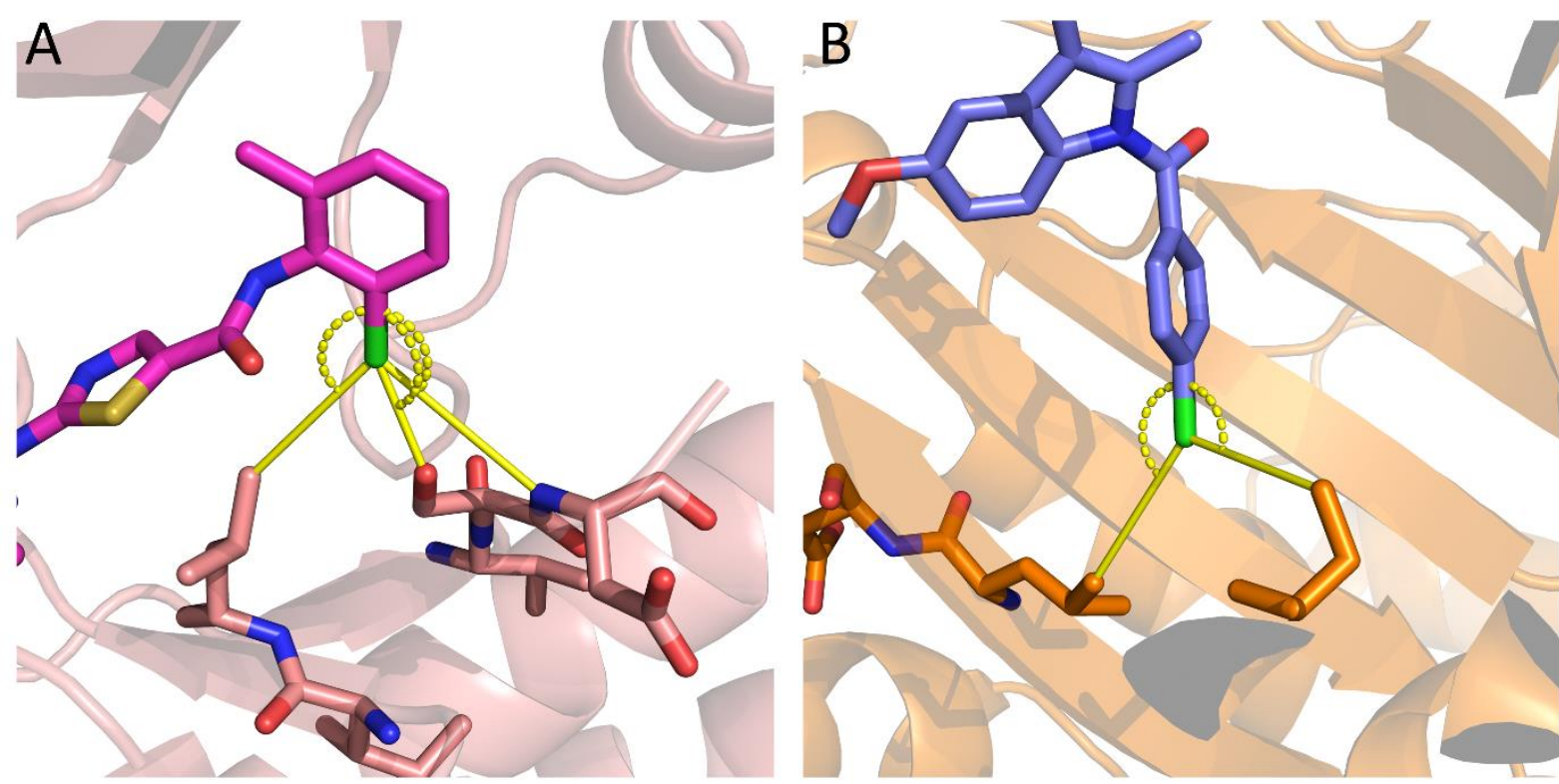

Figure S2. 3D representation of Dasatinib and Indomethacin ligands interacting through their halogen atom. A. Dasatinib chlorine interacting with Ephrin type A receptor kinase domain (PDB id 2y6o, residues leucine 753 , serine 763 and aspartic acid 764) and B. Indomethacin ligand interacting with glyoxalase receptor (PDB id 4kyk, residues leucine 61 and isoleucine 180). 
<smiles>Clc1ccccc1</smiles>

[933]<smiles>FCF</smiles>

[138]<smiles>Clc1cccnc1</smiles>

[37]<smiles>Fc1ccccc1</smiles>

[675]<smiles>Fc1cccc(F)c1</smiles>

[133]<smiles>Fc1ccccc1Cl</smiles>

[36]<smiles>FC(F)F</smiles>

[612]<smiles>Clc1ccccc1Cl</smiles>

[64]<smiles>Cc1cccc(Cl)c1</smiles>

[35]<smiles>Clc1ccccc1Cl</smiles>

[185]<smiles>Fc1cccc(F)c1</smiles>

[47]<smiles>Ic1ccccc1</smiles>

[40]<smiles>Clc1cccs1</smiles>

[33]<smiles>Brc1ccccc1</smiles>

[165]
] ]<smiles>Fc1ccc(F)c(F)c1</smiles>

[31]

Figure S3. Schematic representation of recurrent molecular fragments containing halogen atoms (propensity in brackets). 
Distribution of distance-based contacts

per halogen atoms

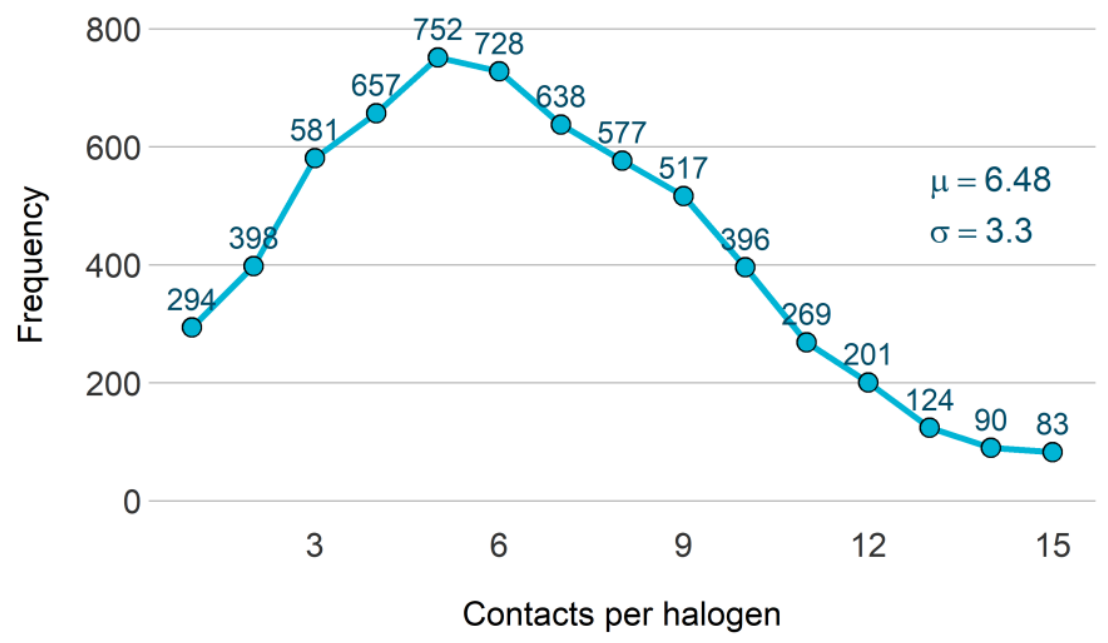

Figure S4. Quantitative distribution of protein atoms detected in the vicinity of each halogen using a distance-based detection method. 

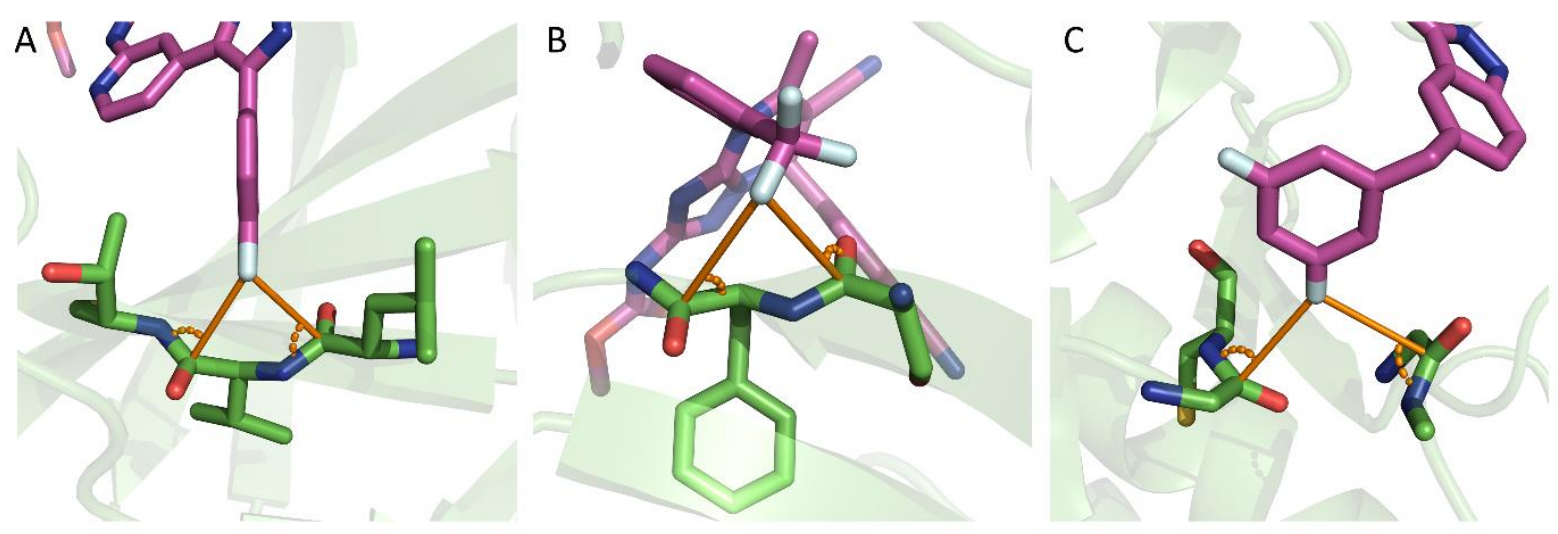

Figure S5. 3D representation of fluorine interacting (orange) with multiple positive dipole moments of amide carbon in peptide (represented in green). A. Human p38 $\alpha$ MAP kinase 14 residues leucine 104 and valine 105 with imidazole pyridine inhibitor (PDB id 5ml5). B. Neutrophil Elastase serine 214 and phenylalanine 215 involved (PDB id 5a8y) C. ALK tyrosine kinase receptor asparagine 1254 and glycine 1269 with Entrectinib (PDB id 5fto). 


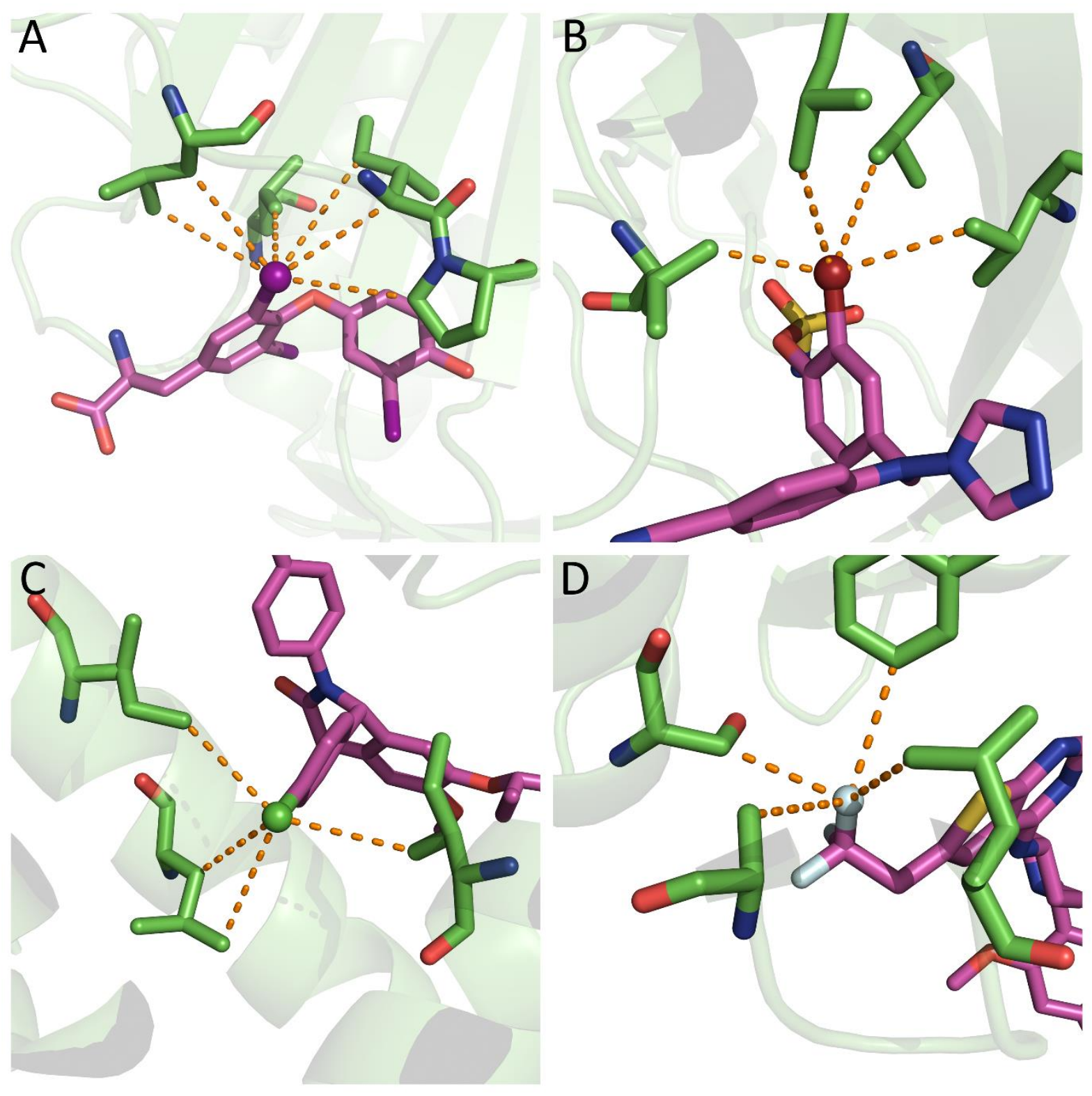

Figure S6. 3D Illustration of hydrophobic-rich environment surrounding halogen atoms (hydrophobic contact displayed in orange dash). A. Proliferating cell nuclear antigen interacting with iodine ligand (purple sphere, PDB id 3vkx) B. Carbonic anhydrase 2 receptor interacting with bromine ligand (red sphere, PDB id 1wq0) C. E3 ubiquitin-protein ligase Mdm2 receptor interacting with chlorine ligand (green sphere, PDB id 4zyi) D. Menin protein interacting with fluorine ligand (white sphere, PDB id $5 \mathrm{db} 1)$. 


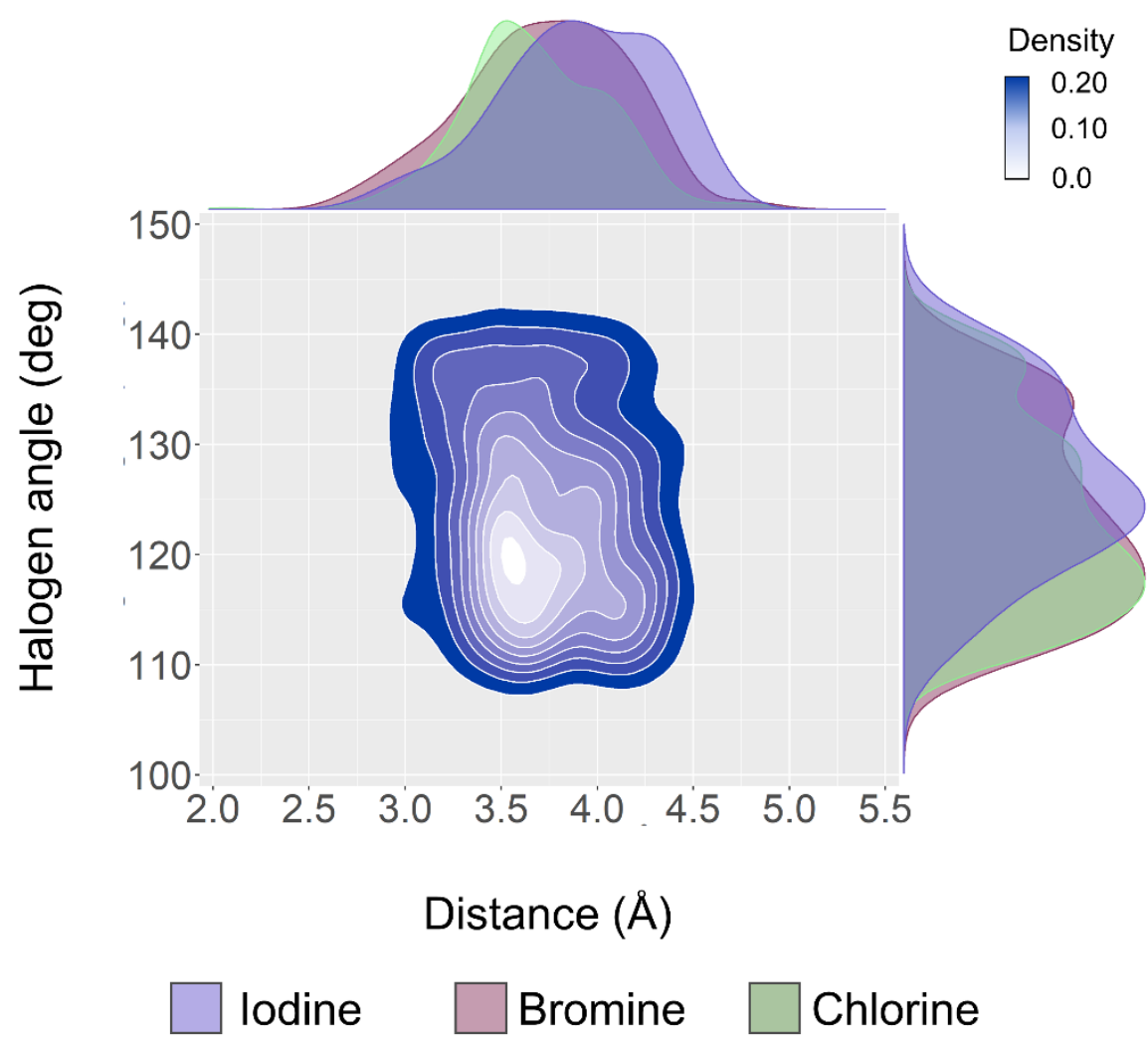

Figure S7. Distribution of geometric descriptors, halogen angle and distance, of polar contact surrounding neutral surface of heavy halogens. 
Evolution of halogenated ligand in the PDB

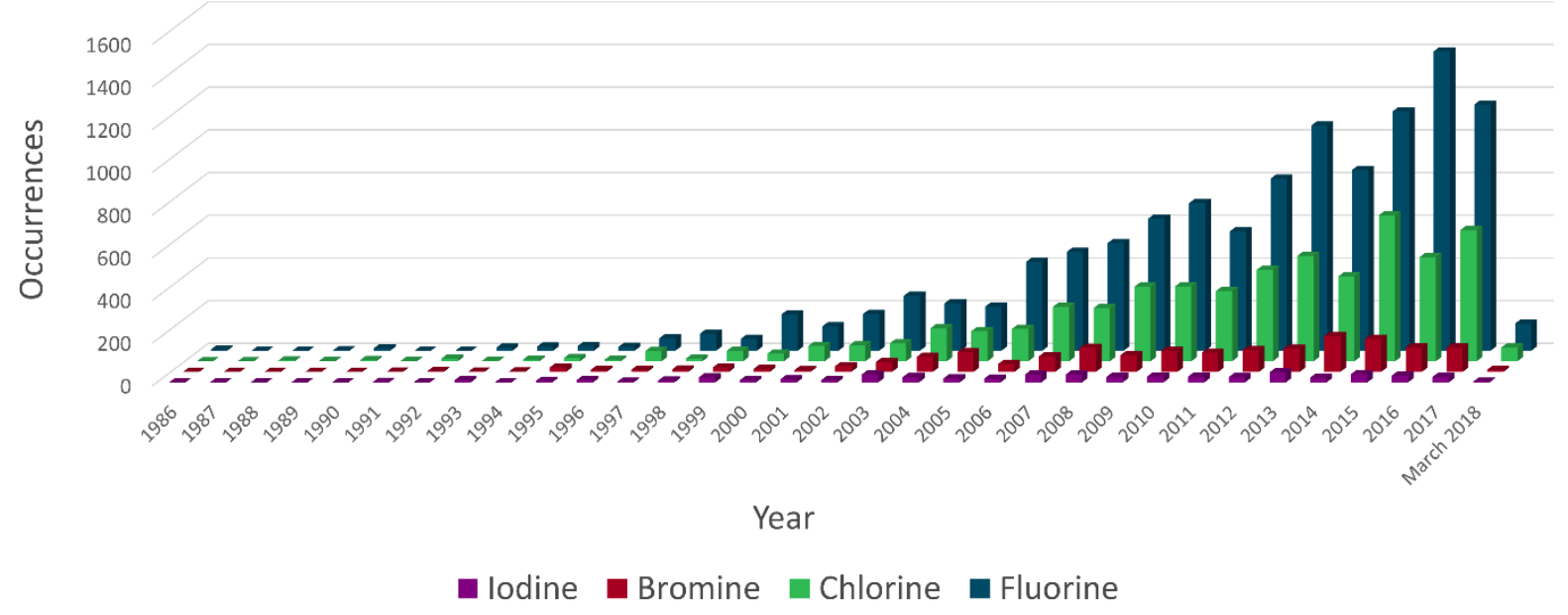

Figure S8. Evolution of halogen atom prevalence in RCSB PDB ligand entries per year and per element. 


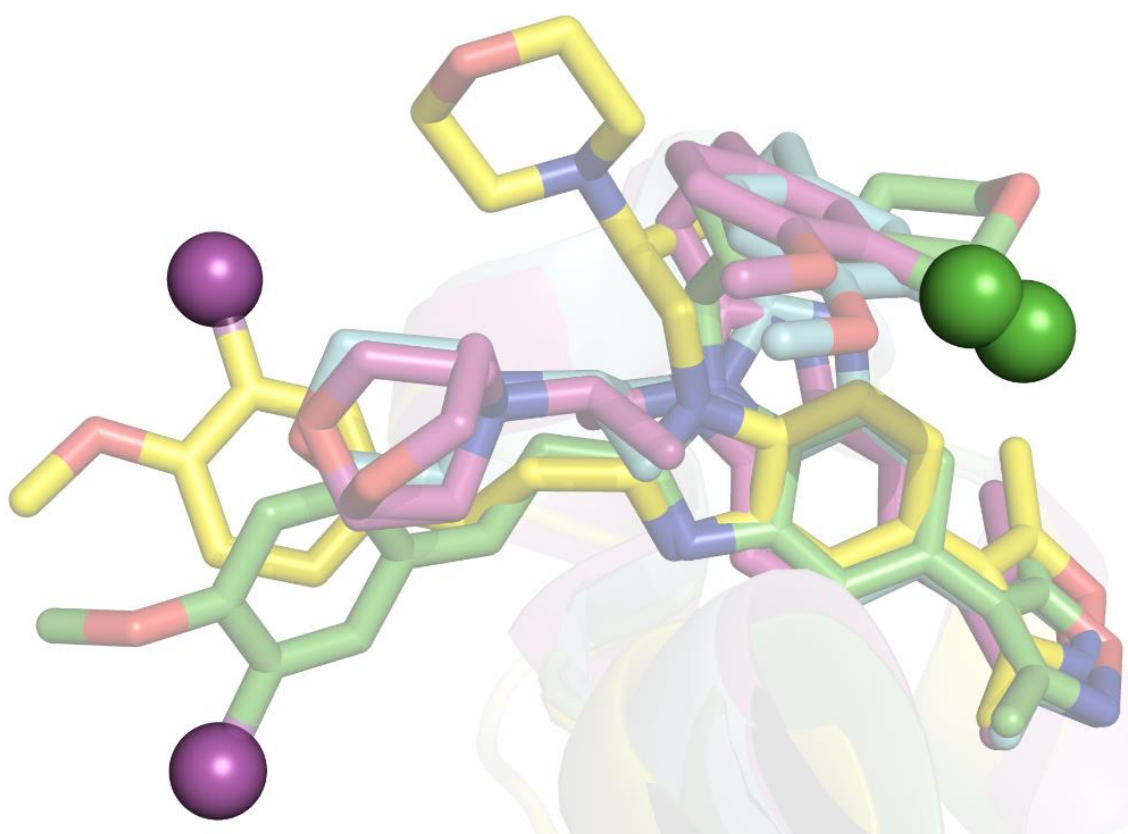

Figure S9. Superposed binding modes of dimethylisoxazol on bromodomain-containing protein 2 highlighting the variable spatial position of its chlorine atom (represented as spheres) in flexible (purple) and recurrent binding modes (green, PDB ids 5bt3, 5bt4, 5bt5, 4nr7). 


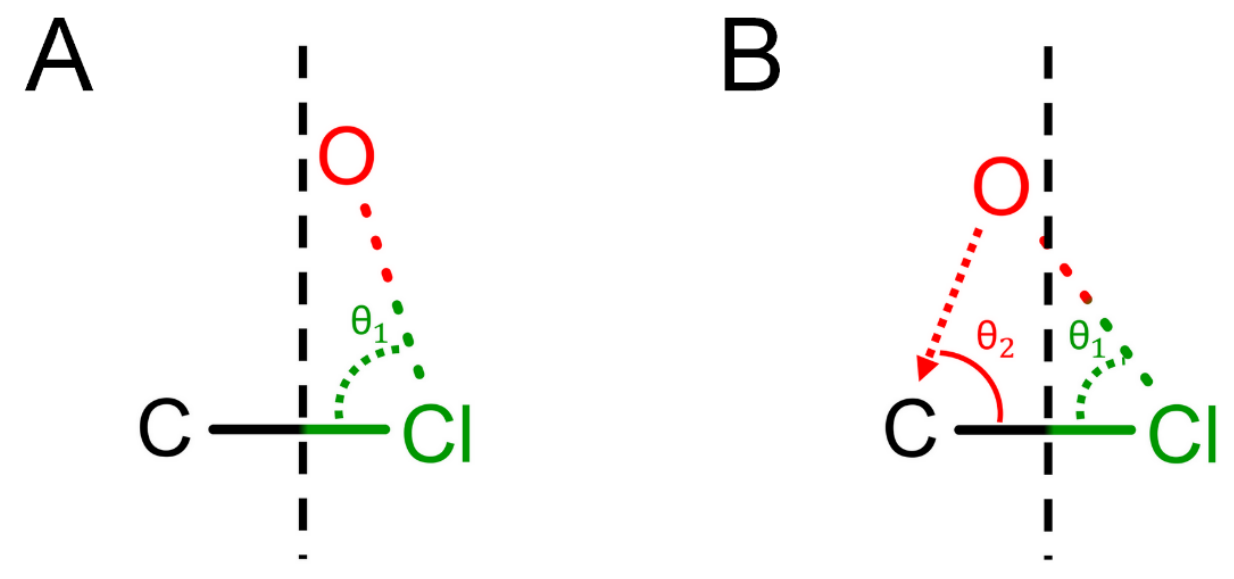

Figure S10. 2D representation of isosceles rule used to define halogen surface accessibility. A. Cases where $\theta_{1}$ is greater than $70^{\circ}$, i.e. oxygen interact with chlorine. $B$. Cases where $\theta_{1}$ is smaller than $\theta_{2}$ i.e. less than $70^{\circ}$ and interacts with the covalently bonded carbon. 
A

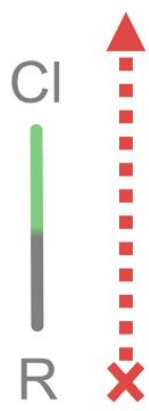

C

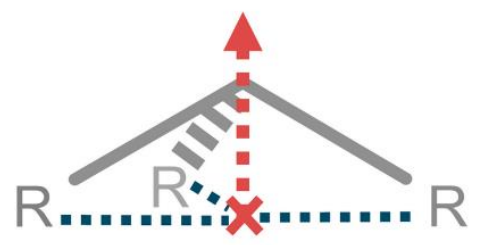

B

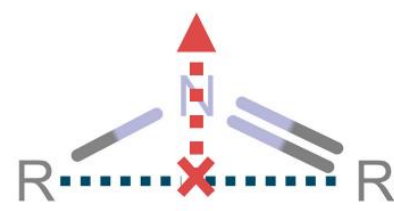

$\mathrm{D}$

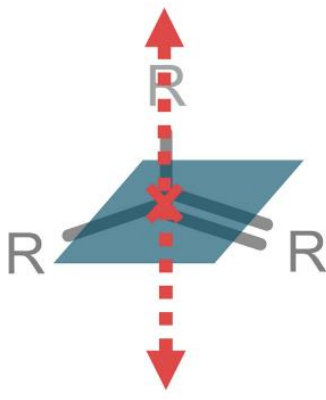

Figure S11. Representation of generated vectors to assess angles between two interacting atoms. A. vector along covalent bond if one covalent atom. B. Bent configuration: vector between center of mass (red cross) of two covalent heavy atoms and interacting atom. C. Trigonal pyramidal configuration: vector between center of mass of two covalent heavy atoms and interacting atom. $D$. Trigonal planar: plane (blue) normal vector centered on interacting atom directed toward the other interacting atom. 


\begin{tabular}{|c|c|c|}
\hline Protein & Occurrences & Medical application \\
\hline$\beta$-secretase 1 (BACE1) & 146 & $\beta$-amyloid in Alzheimer \\
\hline Carbonic Anhydrase 2 (CA) & 74 & Glaucoma \\
\hline Cyclin-Dependant Kinase 2 (CKD2) & 64 & NA \\
\hline Genome Polyprotein & 62 & Anticoagulant \\
\hline Coagulation Factor Xa (F10) & 61 & Anti-tumor \\
\hline Estrogen Receptor Alpha (ER) & 57 & Anti-tumor \\
\hline E3 Ubiquitin-protein ligase (MDM2) & 56 & Anti-tumor, inflammatory \\
\hline Bromodomain (BRD4) & 54 & Immune disorder \\
\hline Nitric oxide synthase (NOS) & 46 & Carcinogenesis \\
\hline Heat Shock Protein (HSP90) & 45 & Anticoagulant \\
\hline Prothrombin (F2) & 42 & \\
\hline
\end{tabular}

Table S1. Occurrences of highly recurrent protein observed in our dataset complexed with halogenated ligand and their corresponding medical application. 


\begin{tabular}{|c|c|c|}
\hline Halogen & Protein & Occurrences \\
\hline $\mathrm{Cl}$ & Coagulation Factor Xa & 48 \\
\hline $\mathrm{Cl}$ & E3 Ubiquitin-protein ligage MDM2 & 26 \\
\hline $\mathrm{Cl}$ & Prothrombin & 19 \\
\hline $\mathrm{Cl}$ & Cldose Reductase & 10 \\
\hline $\mathrm{Br}$ & Methionyl-tRNA synthetase & 9 \\
\hline $\mathrm{I}$ & Dual specificity mitogen-activated protein kinase kinase 1 & 9 \\
\hline $\mathrm{Cl}$ & 3-secretase 1 & 8 \\
\hline $\mathrm{Cl}$ & 3-phosphoinositide-dependent protein kinase 1 & 8 \\
\hline $\mathrm{Cl}$ & \\
\hline
\end{tabular}

Table S2. Number of observations per protein and halogen where halogen bonds were detected in our dataset. 


\begin{tabular}{|c|c|c|}
\hline Residue & Individual contacts & Aromatic contacts \\
\hline Trp & 944 & 357 \\
\hline Tyr & 1665 & 655 \\
\hline Phe & 1876 & 906 \\
\hline His & 702 & 294 \\
\hline
\end{tabular}

Table S3. Comparison of halogen - aromatic contacts detected with different detection methods. "Individual contacts" refers to a method where between a halogen and an aromatic atom is counted while "Aromatic contacts" considers one contact only between the halogen and aromatic center of mass. 